\title{
Hormonal regulation of uterine chemokines and immune cells
}

\author{
Dong-Wook Park' ${ }^{1}$ Kwang-Moon Yang ${ }^{2}$
}

'Laboratory of Reproductive Biology and Infertility, ${ }^{2}$ Department of Obstetrics and Gynecology, Cheil General Hospital and Women's Healthcare Center, Kwandong University College of Medicine, Seoul, Korea

The ultimate function of the endometrium is to allow the implantation of a blastocyst and to support pregnancy. Cycles of tissue remodeling ensure that the endometrium is in a receptive state during the putative 'implantation window', the few days of each menstrual cycle when an appropriately developed blastocyst may be available to implant in the uterus. A successful pregnancy requires strict temporal regulation of maternal immune function to accommodate a semi-allogeneic embryo. To preparing immunological tolerance at the onset of implantation, tight temporal regulations are required between the immune and endocrine networks. This review will discuss about the action of steroid hormones on the human endometrium and particularly their role in regulating the inflammatory processes associated with endometrial receptivity.

Keywords: Immunology; Endometrium; Immune tolerance; Sex steroid hormone; Inflammation; Blastocyst; Embryo; Chemokine; Implantation window; Human

\section{Introduction}

The menstrual cycle of women is precisely controlled by endocrine, autocrine and paracrine factors regulating follicular development, ovulation, luteinisation, luteolysis, and the growth and differentiation of the endometrium. The ultimate function of the endometrium is to allow the implantation of a blastocyst and to support pregnancy. The human endometrium is a dynamic tissue that undergoes repeat cycles involving sequential proliferation, differentiation, breakdown and repair. These cycles of tissue remodeling ensure that the endometrium is in a receptive state during the putative 'implantation window', the few days of each menstrual cycle when an appropriately developed blastocyst may be available to implant in the uterus. The

Received: Dec 12, 2011 · Revised: Dec 16, 2011 · Accepted: Dec 17, 2011 Corresponding author: Kwang-Moon Yang

Department of Obstetrics and Gynecology, Cheil General Hospital and Women's Healthcare Center, Kwandong University College of Medicine, 1-19 Mukjeong-dong, Jung-gu, Seoul 100-380, Korea

Tel:+82-2-2000-7590 Fax:+82-2-2265-5621 E-mail:km1yang@naver.com

This is an Open Access article distributed under the terms of the Creative Commons Attribution Non-Commercial License (http://creativecommons.org/licenses/by-nc/3.0/) which permits unrestricted non-commercial use, distribution, and reproduction in any medium, provided the original work is properly cited. term 'endometrial receptivity' refers to the ability of the uterine lining to accept and accommodate a nascent embryo, resulting in a successful pregnancy [1].

One of the roles of the immune system is to identify non-self antigens and destroy them. During pregnancy, fetal expressed paternal antigens render themselves foreign (non-self), and thus the maternal immune system must tolerate the semi-allogeneic fetus to support the pregnancy. The term 'immune tolerance' has been subjected since first recognized by Billingham et al. [2]. Both implantation and menstruation occur under the control of steroid hormones and are regarded as inflammatory events characterized by leukocyte infiltration and increased inflammatory mediator expression in the endometrium [3]. The modulation of inflammatory events toward immune tolerance in the endometrium by the sex steroid hormones involves a highly complex network of inflammatory mediators and immune cells, which prepare the endometrium for embryo implantation [4].

This review will focus on the actions of steroid hormones on the human endometrium and particularly their role in regulating the inflammatory processes associated with endometrial receptivity. 


\section{Uterine mucosal immune environments}

Mucosal surfaces are in contact with an environment rich in microorganisms. Despite this, they have a low incidence of infection, as mucosal host defense mechanisms create a hostile environment for potential pathogens, minimize inappropriate microbial load and detect and respond appropriately to pathogen challenges. The uterine mucosa is unique amongst other mucosal sites, because it undergoes regular changes in structure under the influence of sex steroids [5]. The seminal plasma introduced during intercourse in the mouse, pig and human female reproductive tract has been shown to induce local inflammatory changes [6]. A considerable proportion of the transforming growth factor (TGF)- $\beta$ synthesized in male accessory glands, particularly the seminal vesicle in rodents and the prostate in humans is secreted into the fluids that contribute to the ejaculate [7]. The TGF- $\beta$ are key regulators of several aspects of the immune responses including lymphocytes, macrophages and dendritic cells [8]. TGF- $\beta$ also promotes conversion of $\mathrm{CD}^{+} 6^{+}$peripheral blood natural killer (NK) cells into CD16- NK cells in vitro [9]. TGF- $\beta$ derived from seminal plasma may affect the maternal immune response in pregnancy through promoting type 2 and/or Th3 immunity to paternal antigens from the outset of their introduction to the female [10]. This result indicates that TGF- $\beta$ may play a pivotal role in maternal immune tolerance to the fetal 'semi-allograft'. Furthermore, implantation and live birth rates following IVF treatment are significantly improved when women are exposed to semen at the beginning of pregnancy [11]. TGF- $\beta$ is a well-known immune-modulating cytokine with pivotal roles in inducing active immune tolerance in peripheral and mucosal tissues. It is abundant in seminal plasma and is largely account for the immune tolerance activity in uterine mucosa [7].

An infection-free environment in the uterus is a crucial for successful implantation and pregnancy. Similar to other mucosal surfaces, the female reproductive tract expresses molecules of the innate immune system, which are important in preventing infection [4]. Implantation, and in particular trophoblast invasion of the endometrium, represents a breach of the mucosal barrier and thus an increased expression of the innate immune molecules may be necessary to ensure effective defense against potential infection [12]. In addition, recent data have suggested that Toll-like receptors (TLRs) may be activated by endogenous ligands produced as a result of tissue damage and sterile inflammation [13]. Pattern recognition receptors (PRRs) including the TLRs and nuclear oligomerization domain proteins (NODs) and effector molecules of the innate immune system such as defensins, secretory leukocyte protease inhibitor (SLPI) and elafin are present in the endometrium [4]. This is relevant to endometrial physiology as implantation may be considered an example of sterile inflammation and production of endogenous ligands may modulate the inflammatory response via PRRs [14]. The immune tolerance and the innate immunity of the endometrium required for a successful implantation are in conflict with each other. This is an area that warrants further investigations.

\section{Hormonal regulation of uterine chemokines}

Chemokines are key regulators of cell migration, and in leukocytes they alter the expression of cellular adhesion molecules and extra cellular matrix (ECM) components that sequentially elicit key changes in the architecture of a cell, allowing migration. The binding of a chemokine to its receptor on a specific leukocyte up-regulates the expression of adhesion molecules, thus promoting leukocyte adhesion to the endothelium and chemotaxis along a concentration gradient [15]. So far, around 50 chemokines, which bind to 18 different chemokine receptors, have been identified in humans. These are members of the seven-transmembrane receptor family. Initially, chemokines were identified as modulators of the immune response [16].

There is clear evidence that sex steroid hormones can directly and/ or indirectly affect the expression of a variety of chemokines during the menstrual cycle [17-19]. Among the CC and CXC chemokine families, immunohistochemistry has revealed that endometrial endothelial, epithelial, and stromal cells express CCL4/macrophage inflammatory protein (MIP)-1 $\beta$, CCL5/Regulated upon Activation, Normal Tcell Expressed, and Secreted (RANTES), CCL7/monocyte chemotactic protein (MCP)-3, CCL19/Epstein-Barr-virus-induced molecule 1 ligand chemokine (ELC), CCL21/secondary lymphoid tissue chemokine (SLC), CXCL9/Monokine Induced by Gamma interferon (Mig) and CXCL10/ Interferon gamma-induced protein (IP)-10, and that their expression levels vary depending on the phase of the menstrual cycle, being higher in the secretory phase than in the proliferative phase [20]. Along with this, several chemokines such as CX3CL1, CCL7, CCL14 and CCL4 were up-regulated in the mid-secretory phase endometrium and maintained in early pregnancy. These factors were identified as chemoattractants for macrophages and NK cells, and accumulate at the implantation site. In addition to this, Mokhtar et al. [21] have reported that CXCL14 is likely to be regulated by progesterone in human endometrium and that it may exert a chemo-attractive effect on uNK cells and in part be responsible for their clustering around the epithelial glands. Jones et al. [22] have reported that macrophage derived chemokine (MDC), MCP-3, fractalkine (FKN), hemofiltrate CC chemokine (HCC)-1, HCC-4 and MIP-1 $\beta$ are upregulated in the metrium during the implantation window, when they may alter leukocyte behaviors.

Chemokines can directly and/or indirectly control the uterine cell function and implantation. IFN- $\gamma$ induced expression of CXCL11 in the endometrial epithelial cells and that CXCR3. IFN- $\gamma$ and CXCL11 in- 
duced apoptosis of endometrial epithelial cells in vitro, this data speculate that embryo-derived IFN- $\gamma$ kills endometrial epithelial cells via chemokine expressions in endometrial cells for implantation [23].

\section{Hormonal regulation of uterine immune cells}

Tibbetts et al. [24] have suggested that estradiol leads to a pro-inflammatory response within the uterus and progesterone creates an anti-inflammatory environment by regulating the expression of various cytokines. These cytokines (interleukin [IL]-11 and IL-15) also regulate the process of uterine stromal cells and can affect the proliferation and differentiation of T helper cells and natural killer (NK) cells within the uterus $[25,26]$.

It has been proposed that progesterone's effects on T cells are mediated through the blockade of a $\mathrm{K}^{+}$channel, which rapidly inhibits the $\mathrm{Ca}^{2+}$ signaling pathway, thus inhibiting production of the major proliferative cytokine for T cells [27]. Experimental data have demonstrated that peripheral blood NK cells $\left(C D 56^{\operatorname{dim}} \mathrm{CD} 16^{+}\right)$, but not CD$56^{\text {bright }}$ CD16 NK cells, express both classical progesterone receptor $(\mathrm{PR})$ isoforms $\left(\mathrm{PR}_{\mathrm{A}}\right.$ and $\mathrm{PR}$ ) and progesterone induces caspase-dependent cell death, which is reversed by two different anti-progestin, ZK 98.299 and RU 486, this results supporting the involvement of classical PR isoforms (Figure 1) [28]. Furthermore, the lack of PR expression on $\mathrm{CD} 56^{\text {bright }} \mathrm{CD} 16 \mathrm{NK}$ cells provides an additional idea that they might represent the PBNK precursors that are selectively recruited into the endometrium where they differentiate to become the uterine NK cells. Additionally, these findings may be relevant to progesterone and NK cell function in human reproduction in terms of immune tolerance. The action of progesterone on endometrium is summarized in Figure 2.
Hirano et al. [29] have reported data about estradiol on T cell function. The authors proposed that $17 \beta$-estradiol can enhance NF-KB signaling in T cells and thus affect $T$ cell survival. The reproductive immunological function of estrogen is still remains to be investigated, because estrogen shows a diverse range of functions depending on its concentration.

\section{Uterine NK cells}

NK cells are the predominant lymphocyte population present in the uterus [30]. Phenotypic and functional analysis of first trimester human decidual CD56 $6^{\text {bright }}$ CD16- NK cells indicate that uterine NK (uNK) cells are a unique population distinct from the blood counterpart $\left(\mathrm{CD} 56^{\mathrm{dim}} \mathrm{CD} 16^{+}\right)$, and recent findings have demonstrated that they exhibit a unique transcriptional profile [31]. The absolute numbers of uNK cells present in the endometrium increases after ovulation although the proportion in relation to other leukocyte subtypes remains constant (30\%) across the menstrual cycle. It is only when pregnancy occurs that this proportion increases to around $70 \%$ of the total leukocyte population [32]. It has been reported that chemokines pro-

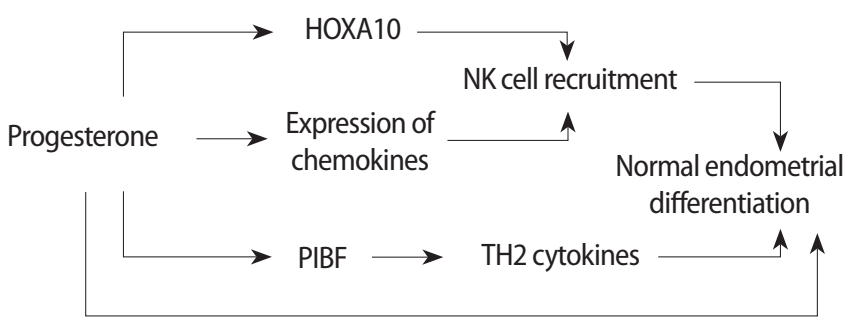

Figure 2. Action of progesterone on endometrium in establishment and maintenance of pregnancy. NK, natural killer; PIBF, progesterone induced blocking factor.

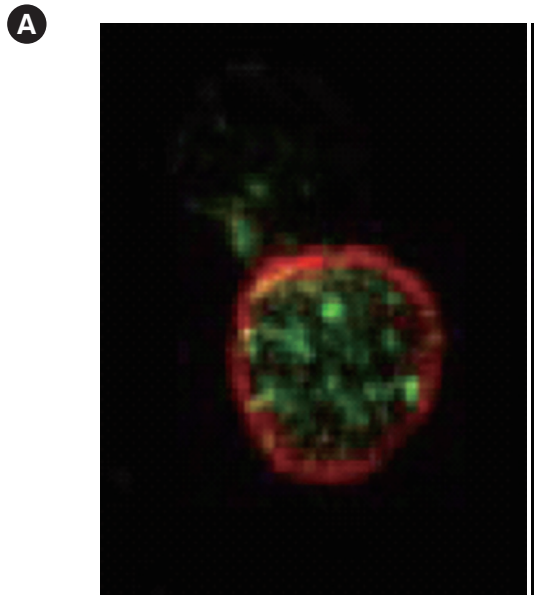

CD56+PR+

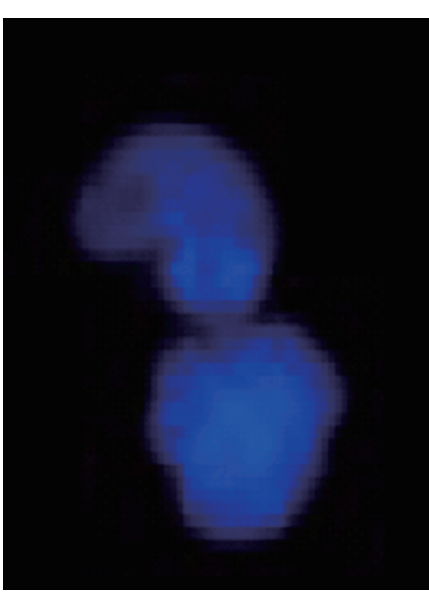

DAPI

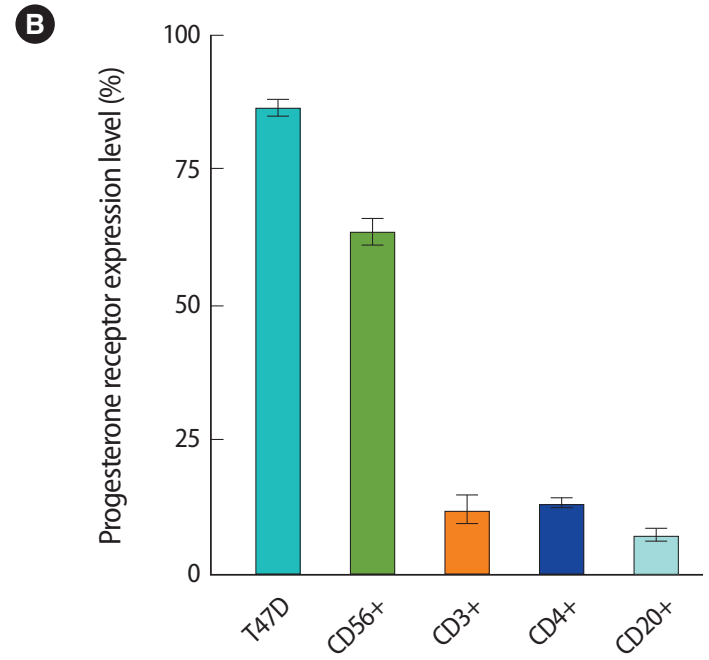

Figure 1. Presence of progesterone receptor (PR) on peripheral blood natural killer cells by confocal microscopy (A), and flow cytometry (B) (Modified from Arruvito et al. J Immunol 2008;180:5746-53 [28]). DAPI , 4,6-diamidino-2-phenylindole. 
duced by trophoblast or endometrial cells, such as CXCL9/Mig, CXCL10/ IP-10 and CXCL12/SDF-1, or CCL4/MIP-1 $\beta$ and CCL3/MIP-1a can support the peripheral blood NK cell chemotactic response [33].

A large body of evidence indicates that there are different NK cell subsets between the peripheral blood and the endometrium (uNK)/ decidua (dNK). Campbell and co-workers have provided the first evidence that distinct $\left(\mathrm{CD} 56^{+} \mathrm{CD} 16^{+}\right.$and $\left.\mathrm{CD}^{2} 6^{+} \mathrm{CD} 16^{-}\right)$peripheral blood NK cell subsets have a unique repertoire of chemokine receptors [34]. CD16 ${ }^{+}$NK cells homogenously express high levels of CXCR1 and CX3CR1, low levels of CXCR2 and CXCR3 and no detectable levels of CXCR5. In contrast, CD16 NK cells express high levels of CXCR3, low levels of CX3CR1, and are negative for CXCR1, CXCR2, and CXCR5. Moreover, both NK cell subsets express high levels of CXCR4, the receptor for CXCL12/SDF-1a/ $\beta$. With respect to the CC chemokine receptor family, these authors found that the majority of NK cells lack the expression of CCR1-7 and CCR9, and only the CD16-NK cell subset expresses high levels of CCR5 and CCR7, the latter molecule mainly involved in the homing of lymphocytes to secondary lymphoid organs. This evidence indicates that the different NK cell subset populations in the peripheral blood and uterus arise from the alternating chemotactic forces between chemokines and their receptors expressed in NK cell subtypes. On the other hand, Keskin et al. [9] have reported that TGF- $\beta$ can promote conversion of $\mathrm{CD} 16^{+}$NK cells into CD16- NK cells. Furthermore, it is possible that dNK cells may originate from precursor cells which residing in uterine tissues or migrate there from blood. Park et al. [35] has reported on the coincidence of pNK and dNK cell populations. This report indicates that pNK cell populations negatively correlates with the gestational period of women with recurrent miscarriage and have a positive correlation with $\operatorname{CD} 56^{+}$ cells in the decidua as well. This data can supports the notion that peripheral blood can be a major source of dNK cells. Although a large number of experimental results has been reported, the origin of uNK and dNK cells has not yet been clearly defined.

Accumulating evidence indicates that uNK cells contribute to the successful implantation and maintenance of pregnancy [36-38]. uNK cells exhibit lesser cytotoxic activity as compared with the peripheral blood counterpart, although in humans they have been shown to express a number of activating receptors including NKG2D, CD244, NKp30, NKp44, and NKp46, in human and are endowed with an intact cytolytic machinery, namely perforin, and granzymes [39]. Although uNK cells exhibit poor killing activity, they are capable of secreting a wide array of cytokines and chemokines without stimulation, suggesting that they have undergone activation in the decidua [40]. uNK cells have ability to produce angiogenic factors such as vascular endothelial growth factor (VEGF), placental growth factor (PIGF), and angiopoietin 2 in both mice and humans [36,40]. These results have supported the idea that the major role of uNK cells is the con- trol of decidual angiogenesis and placental development.

\section{Uterine mast cells}

Mast cells (MCs) have been known to be mediators of allergic reactions, but it has now been recognized that their immune function extends far beyond playing critical roles in a variety of non-allergic innate [41] and adaptive [42] immune responses. MCs exhibit clear tissue-specific phenotypes [43]. Early studies about MCs isolated from human myometrium revealed that they share more functional characteristics with lung MCs than skin MCs. For example, uterine MCs responded to lgE stimulation by releasing of histamine, leukotriene C4 and prostaglandin (PG) D2 [44]. The number of MCs in the endometrium is low, and those are predominantly localized in the basal layer [45]. Some evidence indicates that MCs and their products, including histamine, may participate in the development of the placenta through the regulation of trophoblast invasion and growth. In particular, histamine can increase trophoblast expression of $a \mathrm{~V} \beta 3$ integrin, a key marker of extravillous trophoblasts [46,47]. Mast cell activation and functions can be affected by sex steroid hormones. Zaitsu et al. [48] reported that binding of physiological concentrations of estradiol to a membrane estrogen receptor-a on mast cells initiates a rapid onset and progressive influx of extracellular $\mathrm{Ca}^{2+}$, which supports the synthesis and release of allergic mediators. Estradiol also enhances IgE-dependent mast cell activation, resulting in a shift of the allergen dose response. However the trigger for MCs activation and their functions in the implantation needs further investigation.

\section{Uterine T cells}

There is clear evidence to suggest that the maternal T lymphocytes at the feto-maternal interface play an important role in fetal survival and development. In mice, TH2-type cytokines (IL-4, IL-5, and IL-10) are detectable at feto-maternal interface during the period of gestation, whereas IFN- $\gamma$ (TH1 cytokine) is transient, being detectable only in the first period [49]. Recent studies in mice and humans suggest that the production of leukemia inhibitory factor (LIF) in the endometrium is an essential requirement for implantation and embryo development [50]. Piccinni et al. [51] have reported that LIF which is produced by endometrial epithelial cells, NK cells and T cells is mainly produced by $\mathrm{TH} 2$-like cells. They also showed that the development of LIF-producing T cells is down-regulated by TH1 inducers, IL-12, IFN-a and IFN- $\gamma$, and up-regulated by IL-4 (TH2 cytokine) and progesterone which promote the differentiation of T cells into TH2 effectors. Interestingly, little or no expression of LIF mRNA was seen in the glandular epithelium of the decidua, although the adjacent CD45 leukocytes were strongly positive [52]. Thus, it seems that the production of LIF in the decidua could be predominantly attributed to the T cells. 


\section{Uterine dendritic cells}

Dendritic cells (DCs) are located within mucosal sites, such as the skin, airways, gut, and decidua. DCs have the unique property of being able to induce both antigen-specific activation and the immune response [53]. DC may also play a role in tolerance induction through the generation of T cells with regulatory properties, which in turn limit the proliferation of effector T cells or delete antigen-specific $T$ cells. Uterine dendritic cells (DCs) within the decidua have been implicated in pregnancy maintenance. DCs serve as antigen-presenting cells with the unique ability to induce primary immune responses. Just as lymphocytes comprise different subsets, DC subsets that differentially control lymphocyte function have been identified. DCs may also act to induce immunologic tolerance and regulation of the T cell-mediated immunity [54].

\section{Gonadotropins on the immune system}

Gonadotropins such as FSH, LH, and hCG are involved in the control of the neuroendocrine response crucial for the regulation of the menstrual cycle, ovulation, and maintenance of the pregnancy. Recent studies have reported that, the receptors for $F S H, L H$, and hCG are expressed on immune cells and they have capacity to influence the immune response. More specifically, it has been shown that $\mathrm{hCG}$ in particular is able to down-regulate immune responses locally and systemically during pregnancy [55]. The divergent immune-modulatory effects of recombinant and urinary-derived FSH, LH, and hCG on human $\mathrm{CD}^{+} \mathrm{T}$ cells have been published by Carbone et al. [56]. Recombinant FSH (r-FSH) and LH (r-LH) alone showed a modest capacity to influence proliferation and cytokine release by $\mathrm{CD}^{+} \mathrm{T}$ cells. Conversely, their addition to T cells in combination with recombinant hCG (r-hCG) induced a powerful down-modulation of T cell proliferation, decreased IFN- $\gamma$ secretion and increased IL-10 production. Thus, the authors suggested that the use of the recombinant preparations in assisted reproductive techniques might be relevant not only for their well-documented endocrine actions but also for their impact on the transient immune tolerance known to favor embryo implantation and progression of pregnancy.

\section{Summary and conclusion}

Endometrial receptivity is commenced by the appropriate expression of marker molecules, phenotypic changes in endometrial tissues, and the extrusion of pinopodes. These morphological and molecular changes of endometrial cells occur under the sequential influence of the sex steroid hormones, estrogen and progesterone. Together with this, successful pregnancy requires strict temporal regulation of maternal immune function to accommodate the semi-allo- geneic embryo. To prepare for immunological tolerance at the onset of implantation, tight temporal regulations are required between the immune and endocrine networks. These mechanisms create a favorable environment for controlling trophoblast invasion. Steroid hormones have a role in regulating immune regulating functions as well. Under the control of sex steroid hormones, immune cells are migrated and differentiated appropriately. Thus, they affect angiogenesis, trophoblast invasion and placentation. Studies on the immunological aspects of endometrial receptivity would provide a data to resolve reproductive problems such as implantation failure and recurrent miscarriages and it would used to be develop controlled ovarian hyperstimulation protocols for assisted reproductive techniques.

\section{Conflict of interest}

No potential conflict of interest relevant to this article was reported.

\section{References}

1. Lessey BA. Assessment of endometrial receptivity. Fertil Steril 2011;96:522-9.

2. Billingham RE, Brent $L$, Medawar PB. Actively acquired tolerance of foreign cells. Nature 1953;172:603-6.

3. Critchley HO, Kelly RW, Brenner RM, Baird DT. The endocrinology of menstruation--a role for the immune system. Clin Endocrinol (Oxf) 2001;55:701-10.

4. King $A E$, Critchley HO. Oestrogen and progesterone regulation of inflammatory processes in the human endometrium. J Steroid Biochem Mol Biol 2010;120:116-26.

5. Quayle AJ. The innate and early immune response to pathogen challenge in the female genital tract and the pivotal role of epithelial cells. J Reprod Immunol 2002;57:61-79.

6. Robertson SA, Mau VJ, Tremellen KP, Seamark RF. Role of high molecular weight seminal vesicle proteins in eliciting the uterine inflammatory response to semen in mice. J Reprod Fertil 1996; 107:265-77.

7. Nocera M, Chu TM. Transforming growth factor beta as an immunosuppressive protein in human seminal plasma. Am J Reprod Immunol 1993;30:1-8.

8. Letterio JJ, Roberts AB. Regulation of immune responses by TGFbeta. Annu Rev Immunol 1998;16:137-61.

9. Keskin DB, Allan DS, Rybalov B, Andzelm MM, Stern JN, Kopcow $H D$, et al. TGFbeta promotes conversion of CD16+ peripheral blood NK cells into CD16- NK cells with similarities to decidual NK cells. Proc Natl Acad Sci U S A 2007;104:3378-83.

10. Robertson SA, Ingman WV, O'Leary S, Sharkey DJ, Tremellen KP. Transforming growth factor beta--a mediator of immune devia- 
tion in seminal plasma. J Reprod Immunol 2002;57:109-28.

11. Tremellen KP, Valbuena D, Landeras J, Ballesteros A, Martinez J, Mendoza $S$, et al. The effect of intercourse on pregnancy rates during assisted human reproduction. Hum Reprod 2000;15:2653-8.

12. King $A E$, Critchley HO, Kelly RW. Innate immune defences in the human endometrium. Reprod Biol Endocrinol 2003;1:116.

13. Zhang Z, Schluesener HJ. Mammalian toll-like receptors: from endogenous ligands to tissue regeneration. Cell Mol Life Sci 2006; 63:2901-7.

14. King AE, Horne AW, Hombach-Klonisch S, Mason Jl, Critchley HO. Differential expression and regulation of nuclear oligomerization domain proteins NOD1 and NOD2 in human endometrium: a potential role in innate immune protection and menstruation. Mol Hum Reprod 2009;15:311-9.

15. Le Y, Zhou Y, Iribarren P, Wang J. Chemokines and chemokine receptors: their manifold roles in homeostasis and disease. Cell Mol Immunol 2004;1:95-104.

16. Kiefer F, Siekmann AF. The role of chemokines and their receptors in angiogenesis. Cell Mol Life Sci 2011;68:2811-30.

17. Dominguez F, Galan A, Martin JJ, Remohi J, Pellicer A, Simon C. Hormonal and embryonic regulation of chemokine receptors CXCR1, CXCR4, CCR5 and CCR2B in the human endometrium and the human blastocyst. Mol Hum Reprod 2003;9:189-98.

18. Zhang J, Lathbury LJ, Salamonsen LA. Expression of the chemokine eotaxin and its receptor, CCR3, in human endometrium. Biol Reprod 2000;62:404-11.

19. DeLoia JA, Stewart-Akers AM, Brekosky J, Kubik C. Stimulation of uterine cell cytokine production by ovarian hormones. Am J Reprod Immunol 2000;44:16-21.

20. Santoni A, Carlino C, Gismondi A. Uterine NK cell development, migration and function. Reprod Biomed Online 2008;16:202-10.

21. Mokhtar NM, Cheng CW, Cook E, Bielby H, Smith SK, CharnockJones DS. Progestin regulates chemokine (C-X-C motif) ligand 14 transcript level in human endometrium. Mol Hum Reprod 2009;16:170-7.

22. Jones RL, Hannan NJ, Kaitu'u TJ, Zhang J, Salamonsen LA. Identification of chemokines important for leukocyte recruitment to the human endometrium at the times of embryo implantation and menstruation. J Clin Endocrinol Metab 2004;89:6155-67.

23. Hirota Y, Osuga Y, Koga K, Yoshino O, Hirata T, Morimoto C, et al. The expression and possible roles of chemokine $\mathrm{CXCL} 11$ and its receptor CXCR3 in the human endometrium. J Immunol 2006; 177:8813-21.

24. Tibbetts TA, Conneely OM, O'Malley BW. Progesterone via its receptor antagonizes the pro-inflammatory activity of estrogen in the mouse uterus. Biol Reprod 1999;60:1158-65.

25. Dimitriadis E, Robb L, Salamonsen LA. Interleukin 11 advances progesterone-induced decidualization of human endometrial stromal cells. Mol Hum Reprod 2002;8:636-43.

26. Dunn $\mathrm{CL}$, Critchley HO, Kelly RW. IL-15 regulation in human endometrial stromal cells. J Clin Endocrinol Metab 2002;87:1898901.

27. Ehring GR, Kerschbaum HH, Eder C, Neben AL, Fanger CM, Khoury $\mathrm{RM}$, et al. A nongenomic mechanism for progesterone-mediated immunosuppression: inhibition of $\mathrm{K}+$ channels, Ca2+ signaling, and gene expression in T lymphocytes. J Exp Med 1998;188: 1593-602.

28. Arruvito L, Giulianelli S, Flores AC, Paladino N, Barboza M, Lanari $C$, et al. NK cells expressing a progesterone receptor are susceptible to progesterone-induced apoptosis. J Immunol 2008;180: 5746-53.

29. Hirano S, Furutama D, Hanafusa T. Physiologically high concentrations of 17beta-estradiol enhance NF-kappaB activity in human T cells. Am J Physiol Regul Integr Comp Physiol 2007;292: R1465-71.

30. King A, Balendran N, Wooding P, Carter NP, Loke YW. CD3- leukocytes present in the human uterus during early placentation: phenotypic and morphologic characterization of the CD56++ population. Dev Immunol 1991;1:169-90.

31. Koopman LA, Kopcow HD, Rybalov B, Boyson JE, Orange JS, Schatz $F$, et al. Human decidual natural killer cells are a unique NK cell subset with immunomodulatory potential. J Exp Med 2003; 198:1201-12.

32. Ho HN, Chao KH, Chen CK, Yang YS, Huang SC. Activation status of T and NK cells in the endometrium throughout menstrual cycle and normal and abnormal early pregnancy. Hum Immunol 1996;49:130-6.

33. Hanna J, Wald O, Goldman-Wohl D, Prus D, Markel G, Gazit R, et al. CXCL12 expression by invasive trophoblasts induces the specific migration of CD16- human natural killer cells. Blood 2003; 102:1569-77.

34. Campbell JJ, Qin S, Unutmaz D, Soler D, Murphy KE, Hodge MR, et al. Unique subpopulations of CD56+ NK and NK-T peripheral blood lymphocytes identified by chemokine receptor expression repertoire. J Immunol 2001;166:6477-82.

35. Park DW, Lee HJ, Park CW, Hong SR, Kwak-Kim J, Yang KM. Peripheral blood NK cells reflect changes in decidual NK cells in women with recurrent miscarriages. Am J Reprod Immunol 2010;63: 173-80.

36. Croy BA, van den Heuvel MJ, Borzychowski AM, Tayade C. Uterine natural killer cells: a specialized differentiation regulated by ovarian hormones. Immunol Rev 2006;214:161-85.

37. Male V, Trundley A, Gardner L, Northfield J, Chang C, Apps R, et al. Natural killer cells in human pregnancy. Methods Mol Biol 2010; 
612:447-63.

38. Moffett A, Hiby SE. How Does the maternal immune system contribute to the development of pre-eclampsia? Placenta 2007;28 Suppl A:S51-6.

39. Tabiasco J, Rabot M, Aguerre-Girr M, El Costa H, Berrebi A, Parant 0 , et al. Human decidual NK cells: unique phenotype and functional properties-a review. Placenta 2006;27 Suppl A:S34-9.

40. Hanna J, Goldman-Wohl D, Hamani Y, Avraham I, Greenfield C, Natanson-Yaron $S$, et al. Decidual NK cells regulate key developmental processes at the human fetal-maternal interface. Nat Med 2006;12:1065-74.

41. Stelekati E, Orinska Z, Bulfone-Paus S. Mast cells in allergy: innate instructors of adaptive responses. Immunobiology 2007;212: 505-19.

42. Galli SJ, Nakae S, Tsai M. Mast cells in the development of adaptive immune responses. Nat Immunol 2005;6:135-42.

43. Kitamura Y. Heterogeneity of mast cells and phenotypic change between subpopulations. Annu Rev Immunol 1989;7:59-76.

44. Massey WA, Guo CB, Dvorak AM, Hubbard WC, Bhagavan BS, Cohan VL, et al. Human uterine mast cells. Isolation, purification, characterization, ultrastructure, and pharmacology. J Immunol 1991;147:1621-7.

45. Sivridis E, Giatromanolaki A, Agnantis N, Anastasiadis P. Mast cell distribution and density in the normal uterus-metachromatic staining using lectins. Eur J Obstet Gynecol Reprod Biol 2001;98: 109-13.

46. Szukiewicz D, Szukiewicz A, Maslinska D, Gujski M, Poppe P, Mazurek-Kantor J. Mast cell number, histamine concentration and placental vascular response to histamine in preeclampsia. Inflamm Res 1999;48 Suppl 1:S39-40.

47. Szewczyk G, Pyzlak M, Smiertka W, Klimkiewicz J, Szukiewicz D. Histamine stimulates alphav-beta3 integrin expression of the human trophoblast through the $\mathrm{H}$ (1) receptor. Inflamm Res 2006; 55 Suppl 1:S79-80.

48. Zaitsu M, Narita S, Lambert KC, Grady JJ, Estes DM, Curran EM, et al. Estradiol activates mast cells via a non-genomic estrogen receptor-alpha and calcium influx. Mol Immunol 2007;44:1977-85.

49. Lin H, Mosmann TR, Guilbert L, Tuntipopipat S, Wegmann TG. Synthesis of T helper 2-type cytokines at the maternal-fetal interface. J Immunol 1993;151:4562-73.

50. Aghajanova L. Leukemia inhibitory factor and human embryo implantation. Ann NY Acad Sci 2004;1034:176-83.

51. Piccinni MP, Beloni L, Livi C, Maggi E, Scarselli G, Romagnani S. Defective production of both leukemia inhibitory factor and type 2 T-helper cytokines by decidual T cells in unexplained recurrent abortions. Nat Med 1998;4:1020-4.

52. Sharkey AM, King A, Clark DE, Burrows TD, Jokhi PP, CharnockJones DS, et al. Localization of leukemia inhibitory factor and its receptor in human placenta throughout pregnancy. Biol Reprod 1999;60:355-64.

53. Huang X, Venet F, Chung CS, Lomas-Neira J, Ayala A. Changes in dendritic cell function in the immune response to sepsis. Cell- \& tissue-based therapy. Expert Opin Biol Ther 2007;7:929-38.

54. Blois SM, Kammerer U, Alba Soto C, Tometten MC, Shaikly V, Barrientos $\mathrm{G}$, et al. Dendritic cells: key to fetal tolerance? Biol Reprod 2007;77:590-8.

55. Schumacher A, Brachwitz N, Sohr S, Engeland K, Langwisch S, Dolaptchieva $M$, et al. Human chorionic gonadotropin attracts regulatory $T$ cells into the fetal-maternal interface during early human pregnancy. J Immunol 2009;182:5488-97.

56. Carbone F, Procaccini C, De Rosa V, Alviggi C, De Placido G, Kramer $D$, et al. Divergent immunomodulatory effects of recombinant and urinary-derived FSH, LH, and hCG on human CD4+ T cells. J Reprod Immunol 2010;85:172-9. 